Papers and Proceedings of the Royal Society of Tasmania, Volume 114, 1980.

(ms. received 16.10 .1979$)$

\title{
DEMYSTIFICATION OF THE MERSEY BLUFF MARKINGS
}

by Peter Murray

lasmanian Museum and Art Gallery, Hobart

(with one table, three text-figures and one plate)

ABSTRACT

MURRAY, P., 1980 ( $31 \mathrm{v}$ ): Demystification - $f$ the Mersey Bluff markings. Pap. Proc.

R. Soc. Tasm., 114: 4l-48 (incl. one plate). https://doi.org/10.26749/rstpp.114.41

ISSN 080-47. Tasmanian Museumand Art Gallery, Hobart, Tasmania, Australia.

The Mersey Bluff markings have been accepted as petroglyphs attributed to the Tasmanian aborigines despite well presented, concise published evidence to the contrary. The site is now a tourist attraction. Historical circumstances and the lack of an ade uate natural explanation for the markings are largely responsible for this state of affairs. Recent geological findings indicate that the colerite in which the markings occur, displays curvi lanar and concentric jointing responsible for many features of the markings. Some characteristics of the markings are similar to those caused by plant exudates from roots or rhizomes which follow natural irregularities in the rocks.

\section{INTRODUCTION}

A.L. Meston (1932) reported the discovery of what were believed to be the first known petroglyphs in Tasmania. He considered the unusual markings on the surface of the dolerite to be conventionalized aboriginal engravings of an astounding assortment of natural entities including a snake, the head of a bird, a leaf and an abalone shell. Also there were geometric patterns "...circles. concentric circles, large ovals with smaller ovals set within and ovals each with a salient which bears a striking likeness to a specialized type of aboriginal stone scraper" (Meston 1932, p.14).

A paper in the same (1932) volume of the proceedings presented the conclusion by E.O.G. Scott that the markings are the result of natural, not human agencies (Scott 1932). Scott listed 19 serious objections to an anthropogenic origin for the features including a careful consideration of the shapes to which descriptive names were applied, comparison of them with known petroglyphs, supposed areal and geographic restriction of the markings and detailed observations on overly deep, overly complex narrow and undercut outlines of many of the figures. That paper should have laid the matter to rest, and undoubtedly would have, were it not for two factors. Probably the most damaging blow to Scott's appraisal of the site was Meston's subsequent, almost immediate discovery of unambiguously genuine petroglyphs at Mount Cameron West on Tasmania's northwest coast (Meston 1933; Rhys Jones, personal communication). This circumstance, in conjunction with Scott's weak explanatory proposition that lichens and 'pneumatalogical' differentiation of the dolerite were responsible for the spectacular intaglios, swirling lines and circles, appears to have given Meston a doubt from which he could benefit. Geologists were forced to discount Scott's hypothesis of pneumatologic differentiation because the Mersey Bluff dolerite is isotropic and totally lacks any evidence of flow layering (Hill 1965). The etching action of slow growing lichens alone in producing markings of the magnitude of the "abalone" $(0.72 \times 0.52 \mathrm{~m}$ greatest depth of groove, $58 \mathrm{~mm}$ ) also seemed untenable. Since 1931, the markings have been listed as being at least possible rock carvings by many authors including Jones (1966), Lourandos (1970), volger (1972), Sims (1977) and Plomley (1977). Werner, a consultant from UNESCO, visited the site in 1970 and pleaded for its preservation. On this basis a museum has been established on the site. 
Peter Murray

Despite claims to the contrary (Sims 1977), the maxkings on Mersey Bluff are radically different from all other petroglyphs yet found in Tasmania (or anywhere else in the world). Bccause of this potentially great contrast in motif and style, positive acceptance or rejection of the markings as being anthropogenic has profound inplications for Tasmanian and Australian prehistory.

\section{THL MLRSEY BLUFF MARKINGS}

Nearly half a century has expired since Meston's description of the sites. Whatever feelings passed among the participants in the debate have long been forgotten, and the Mersey Bluff markings have since become a tourist attraction, complete with museum and souvenir shop. Had it not been for this final development, the question of authenticity of the markings might never have been raised again.

On making a transect of the bluff, one may observe that the markings aro of a continuously varying nature, ranging from uniformly distributed, obviously natural joints to the more sporadic, isolated and variable expressions of the same phenomenon, where the rock surface had recently lain beneath the soil. This characteristic of the Mersey Bluff markings is foremost among Scott's formidable 1ist of damning observations. Scott also drew attention to the extreme variability of the widths and depths of grooves in any single marking. Rock carvings elsewhere in Tasmania show considerably greater uniformity in this respect (Table 1). In addition, the grooves of many of the Mersey Bluff features are extremely narrow for their depth (for example $6 \mathrm{~mm}$ wide by $26 \mathrm{~mm}$ deep) and some grooves are undercut or flask-shaped in cross section (Scott 1932).

Evidence of how the grooves were made is lacking. There is no indication of pecking or hammering, in fact, most of the grooves are very smooth. Some grooves appear to be composed of deep, conjoined elliptical concavities, but these do not resemble marks produced by percussion. The hardness of the dolerite renders abrasion to depths of up to $50 \mathrm{~mm}$ and deep grooves with tight turning radii inconsistent with Tasmanian aboriginal technology.

While Scott's (1932) politely understated suggestion of selective bias in presenting the markings photographically isolated from similar non-descript examples has gone unheeded, some of the most ardent supporters of the human origin hypothesis have shown a genuine ambivalence as to the nature of certain markings. Even Meston (1932) stated that "occasionally the artist has made use of natural uneveness in the rock to make his design stand out more but cracks in the rock have not been used." At present, a popular concession is that many of the carvings could represent natural markings that have been "touched up" by aboriginal artists. Recent publications have also used a bold drawing of the Mersey Bluff. "abalone" (Sims 1977, Volger 1972, Plomley 1977) which tends to simplify and actually modify the shape of this extremely complex feature. At any rate, an examination of the total range of markings easily demonstrates Scott's point: there are numerous "birds heads", "emus", "seals", and "abalones" but none of these is quite right. They have enclosed areas, extra lines or are connected to a series of nondescript markings of the same character.

\section{CURVILINEAR AND CONCENTRIC JOINTING}

It is not my intention to reiterate Scott's (1932) observations which adequately cover every aspect of the problem and upon which I cannot improve. The major shortcoming of Scott's paper is the mechanism responsible for the markings in light of their suspected non-anthropogenic origin.

In 1965, a geologist described some peculiar jointing patterns that he discovered at Mersey Bluff (Hil1 1965). The jointing in the Mersey Bluff sill differs markedly 


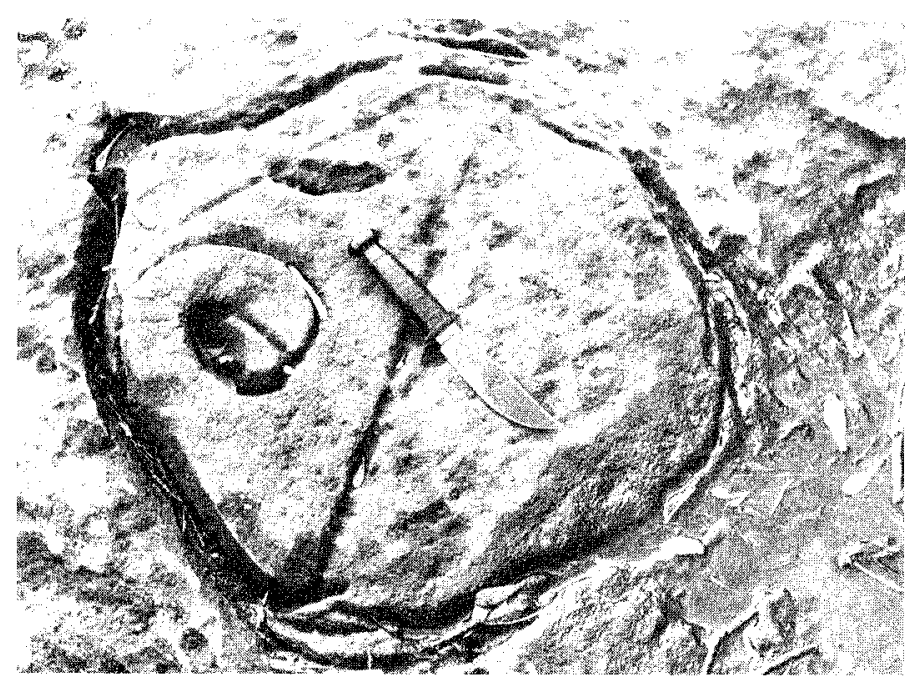

PLATE 1.- Photograph of "abalone" showing ridging adjacent to grooves.

from typical columnar jointing usually found in dolerite outcrops. Instead of sharply defined polygonal and linear joints, the exposed surface of the sill displays curviplanar, concentric, radial and bowtie joint traces occurring in different combinations and being manifested in different ways depending on their position on the Bluff. The heavily weathered portions of the Bluff reveal arcuate, closely-spaced cracks radiating from foci located between 1.5 and 8 metres apart. Foci in close approximation (1.5 3.0 metres form clearly defined joint traces having a radial or bow-tie pattern.

Foci spaced further apart (3.0 - 8.0 metres) tend to form less regular and more widely spaced interlocking festoons (Hil1 1965, p.255). In hand specimens sawn off at right angles to joint planes the joint traces consist of fine curving lines ranging from approximately $10 \mathrm{~mm}$ to $0.25 \mathrm{~m}$ apart (fig.1) .

In heavily weathered exposed portions of the Bluff, in and just above the splash zone, these joints form complex patterns composed of curves, radial fractures, ovals, polygonal figures wi.th rounded edges, platy or wavy textures and irregular pits (fig.2). These exposed surfaces weather relatively rapidly due to a combination of processes that include exposure to frost, exposure to heat, water erosion, chemical weathering and probably salt crystal wedging, creating a complex network of grooves and cracks in the surface of the stone, all of which have their origin as fine, often microscopic joint traces formed by the accumulation of stress in the central zone of the sill and its subsequent explosive release (Hill 1965, p.262). A change in the nature and degree of weathering is evident on ascending the Bluff from about $10 \mathrm{~m}$ to $25 \mathrm{~m}$ above sea level. This portion of the Bluff was covered until recently with a soil mantle and vegetation. The largest and most spectacular markings occur within the $20 \mathrm{~m}$ contour.

Hill's description of structural features of the Mersey Bluff sill correspond with elements of which the so called carvings are composed ffig. 3). These basic structural elements form many geometric shapes that are usually associated with manmade markings. The most striking examples are chevrons, circles, spirals and oval figures (fig.4). Many of the markings combine a number of these elements. 
Peter Murray
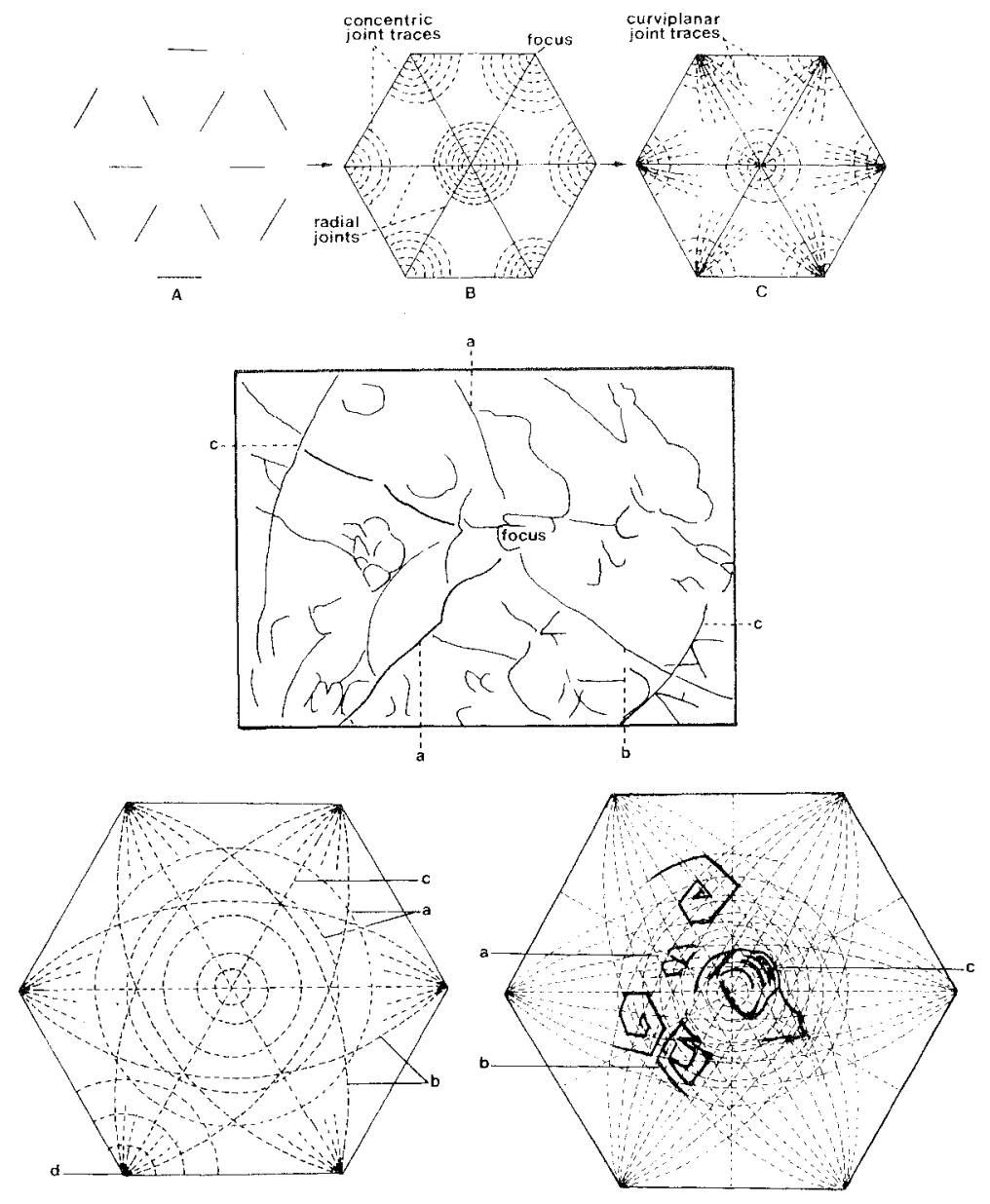

FIG.1.

Top. Origin of curviplanar jointing according to fill (1965): (a) propagation of master columnar joints; (b) concentric fields of stress at foci; (c) propagation of curviplanar factures.

Centre. Top surface of angular pseudocolumn showing: (a) intersecting columnar joints; (b) curviplanar traces radiating from focus; (c) concentric polygonal joints (transecting curviplanars traced from a photograph in Hill 1965)

Bottom (Left). Master columnar joint with idealised fracture pattern superimposed: (a) concentric joints; (b) curviplanar joints; (c) radial or planar joints; (d) focus (modified after Hill, 1965).

Bottom (Right). Mersey Bluff markings superimposed on joint traces: (a) Meston (1932) P1 VII Fig. 5,6; (b) Meston (1932) P! IV Fig.3; (c) Meston (1932) P1 VI Fig.3.

Other figures show development of spirals. Note for example, that (c) is composed of concentric, planar and curviplanar joints. 
The "abalone shell" engraving is the most frequently figured example presumably because it is the best and largest of the supposed carvings (fig.5a). The abalone marking is always shown isolated from many similar adjacent markings which bear no resemblance to any known object but are of the same type as those comprising it. It is composed of chevrons, a spiral, pits, rippling marks, straight lines, and an irregularly subcircular outline (fig.5b,c). While the marking is highly irregular, it is not inconceivable that the fjgure has a crude hexagonal symetry (fig.5b). The presence of the geometric elements in the marking appear to be the result of differential and selective weathering of a series of diamond or wedge shaped patterns formed by surface traces of curviplanar joints over which are imposed the concentric joints, the innermost of which always lie at right angles to curviplanars (fig. $5 \mathrm{~d}$.). The spiral is therefore composed of combined curviplanar, planar and concentric joints. The margin of the marking is composed of concentric joints some of which are closely spaced and are interacting with curviplanar traces emanating from adjacent foci.

However, while the Mersey Bluff markings appear to conform to a peculiar type of jointing phenomenon, the specific agency responsible for selective erosion of the natural1y occurring joint traces remains to be designated. Natural markings rivalling in complexity those at Mersey Bluff occur on granite outcrops on the Blue Tier in northeastern Tasmania (fig.6). These have several important features in common with the Mersey Bluff markings. Most of the markings are curvilinear, many are circular, some have deep narrow grooves, others are broad and shallow. Also like those of Mersey Bluff, many of the maxkings terminate by becoming increasingly shallower and broader (fig.5). The markings occur in apparently homogeneous granite boulders in continuously varying degrees of boldness. Their possible origin can be determined by examining boulders partially covered with vegetation. Lying in similar grooves are numerous examples of tree roots and rootlets. These are almost certainly responsible for the markings. In one case the stump and root of Nothofagus cunninghamiz (myrt le was completely exposed and the relation of the entire root system to the network of grooves could be seen. Professor W.D. Jackson University of Tasmania, (personal communication) suggested that the fern Phymatodes may be responsible for the grooves, with trees such as myrtle following old markings made by that species. Whatever the sequence, roots and rhizomes are known to follow cracks because of better water supply and to obtain mineral nutrients and may well alter the chemical conditions in the rhizosphere by increasing acidity and thus slightly accelerate decomposition.

Many of the grooves in the rocks at Mersey Bluff are similar in cross-section shape and in other previously mentioned features suggesting that the markings are caused by the activity of tree roots that have invaded and exoded by chemical and physical means, segments of curviplanar, radial and concentric joints in the dolerite. As with the granite, decomposition of the feldspar fraction of the dolerite (which constitutes $40-50 \%$ of the rock would lead to local collapse. Because the feldspars are large, and occur in clusters or small clots, these could be related to the localised pitting effect seen on the rock surface.

\section{SUMMARY AND CONCLUSIONS}

The combination of the two factors: 1) that of curviplanar, concentric and radial jointing and 2) the erosive and invasive action of roots, and/or rhizomes as shown by the Blue Tier example, particularly in its attack on feldspars is suggested to be sufficient cause for the Mersey Bluff rarkings.

\section{ACKNOWLEDGEMENTS}

I would like to thank D.R. Gregg for drawing my attention to P.A. Hill's paper on the Mersey Bluff dolerite and Jean Galloway who typed the manuscript. 

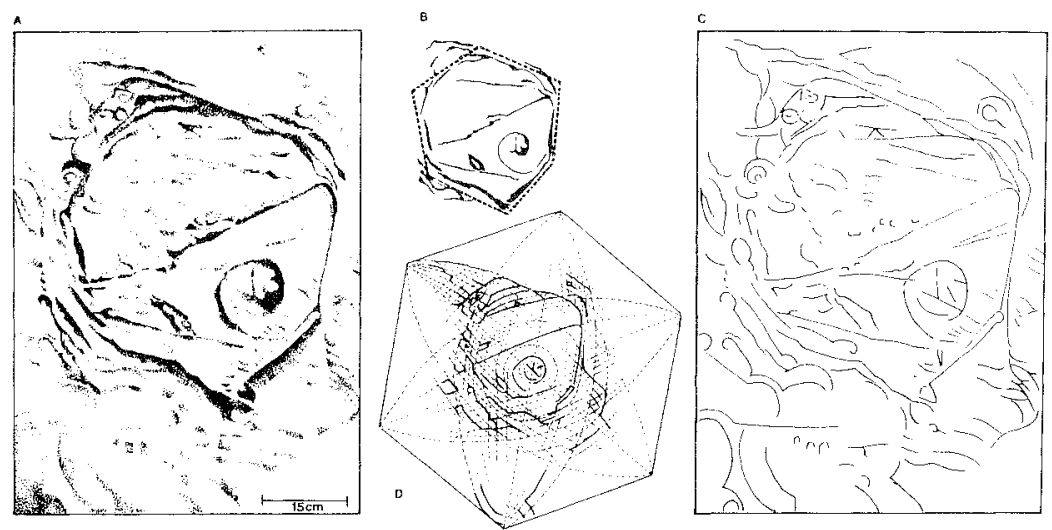

FIG.2.- Analysis of the Mersey Bluff "abalone" figure:

(a) drawing of "abalone" after Meston (1932);

(b) sketch of abalone showing crude hexagonal. outline;

(c) major jointing pattern displayed by the figure;

(d) abalone figure superimposed on idealised joint traces.

The diagram suggests that the spiral is composed of concentric, planar and curviplanar joints. Note explanation of series of intersecting lines in right hand corner as merging curviplanar joints; other details of the figure can be similarly explained as being partially weathered and conjoined joint traces merging from several points of origin within a master column.

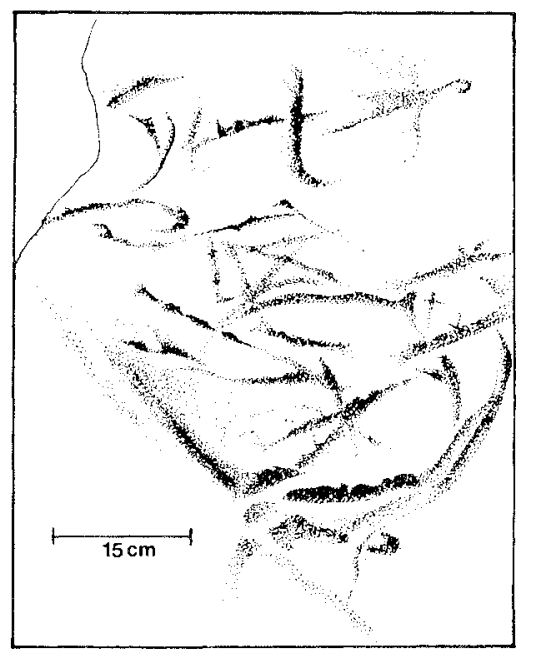

FIG.3 - Sketch of markings on granite in the Blue Tier near Lottah, North East Tasmania. These markings are caused by roots and or rhizomes of trees or ferns. A similar type of weathering is probably responsible for the differential expression of joint traces at Mersey BIuff. 
REFERENCES

Hiil, F.A., 1965: Curviplanar (radial, bow-tie, Eestoon) and concentric jointing in Jurassic dolerite, Mersey Bluff, Tasmania. J. Geol., 73: 255-270.

Jones, R., 1966: A speculative archaeological sequence for northwest Tasmania. Ree. Q. Viet. Mus., 25: 1-12.

Lourandos, H., 1970: A description of the aboriginal archaeological sites in Tasmania. In ABORIGINAL ANTIQUITIES IN AUSTRALIA. Australian Aboriginal Studies 22 Canberra, $35-38$.

Meston, A.L., 1932: Aboriginal rock-carvings on the northwest coast of Tasmania. Pop. Proe. R. Soc. Tasm. 12-19. Soe. Tasm. (1932): $1-6$

Flomley, N.J.B., 1977: THE TASMANIAN ABORIGINES. Adult Education, Hobart, Tasmania. Scott, E.O.G., 1932: Preliminary note on supposed Aboriginal carvings at Mersey Bluff, Devonport. Pap Proc. R. Soc., Fasm, (1931): 112-129.

Sims, P., 1977: Variations in Tasmanian petroglyphs. In Ucko, P.J. (ed.): FORM IN INDIGENOUS ART. Australian Institute of Aboriginal Studies, Canberra: 429-438.

Stockton, J., 1977: Greens creek aboriginal engraving site. National Parks and Wililif'e Service, Tasmania, occasional Paper No.1: 1-13.

Völger, G. Von, 1972: Die Tasmanier. Franz Steiner verlag GMBH Wiesbaden. 